\title{
DEVELOPMENT AND VALIDATION OF RP-HPLC METHOD FOR SIMULTANEOUS ESTIMATION OF TIZANIDINE HCL AND MELOXICAM IN BILAYER MUCOADHESIVE BUCCAL FILMS
}

\author{
MUHAMMAD ZAMAN ${ }^{1,2}$, MUHAMMAD HANIF $^{1 *}$, MUHAMMAD WAHAB AMJAD $^{3}$, \\ HASSAN MURTAZA ${ }^{2}$, MARIA ABDUL GHAFOOR RAJA ${ }^{3}$ and KASHIF UR RAHMAN KHAN ${ }^{4}$ \\ ${ }^{1}$ Department of Pharmacy, Bahauddin Zakariya University Multan, Pakistan \\ ${ }^{2}$ Faculty of Pharmacy, The University of Lahore, Lahore, Pakistan \\ ${ }^{3}$ Faculty of Pharmacy, Northen Border University Arar, Saudi Arabia \\ ${ }^{4}$ Institute of Pharmaceutical Sciences, University of Veterinary and Animal Sciences, Lahore, Pakistan
}

\begin{abstract}
Tizanidine $\mathrm{HCl}(\mathrm{TZN} \mathrm{HCl})$ is a muscle relaxant and Meloxicam (MLX) is a non-steroidal antiinflammatory drug used for various pain disorders. They are extensively used as combination therapy in various pain disorder and the need is to develop a suitable method for their simultaneous determination loaded in a single dosage form. The objective of the study was to develop a simple, specific, and accurate reverse phase high performance liquid chromatographic (RP-HPLC). Method was developed for the simultaneous determination of TZN HCl and MLX. A kromasil C18 $(250 \times 4.60 \mathrm{~mm}$ dimensions, $5 \mu \mathrm{m}$ particle size $)$ column with a mobile phase consisting of methanol : water $(80: 20)$ was used at isocratic mode. $\mathrm{pH}$ of the mobile phase was adjusted to 3.0 by using orthophosphoric acid and $228 \mathrm{~nm}$ was taken as lambda max for the detection of drugs. Flow rate was adjusted to $0.8 \mathrm{~mL} / \mathrm{min}$ at ambient temperature with an average operating pressure of 140 bar. The retention time of TZN HCl was 2.613 min and of MLX was 6.992 min with a resolution of 3.23 and both drugs showed satisfactory linearity in the range of $5-50 \mu \mathrm{g} / \mathrm{mL}$ with a correlation coefficient $\left(\mathrm{R}^{2}\right) 0.09997$ and 0.9993 respectively. The method was validated as per ICH guidelines and found to be précised with less than $2 \%$ relative standard deviation (\%RSD). \% Recoveries of TZN HCl and MLX were in the range of $99.01 \%$ to $100.47 \%$ and $98.18 \%$ to $100.88 \%$ respectively. From the result, it was concluded that the method is suitable for the simultaneous quantification of TZN HCl and MLX.
\end{abstract}

Keywords: simultaneous determination, method development, RP-HPLC, recoveries

TZN HCl, when dried contains not less than $99.0 \%$ and not more than $101.0 \%$ of $\mathrm{C}_{9} \mathrm{H}_{8} \mathrm{ClN}_{5} \mathrm{~S} . \mathrm{HCl}$. It occurs as a white to light yellowish-white crystalline powder. It is soluble in water, slightly soluble in ethanol and practically insoluble in acetic anhydride and in acetic acid. The usual initial daily dose in the management of spasticity is the equivalent of $2 \mathrm{mg}$ of the base given as a single dose. In the treatment of painful muscle spasm, TZN $\mathrm{HCl}$ is given in doses equivalent to 2 to $4 \mathrm{mg}$ of the base three times daily. Clinically, non-steroidal anti-inflammatory drugs (NSAIDs) are the most frequently prescribed by physicians for inflammatory disorders. Meloxicam [4hydroxy-2methyl-N- (5-methyl-2-thiazolyl)-2H-1,2benzothiazine-3- carboxamide1,1-dioxide], is one of the most commonly prescribed NSAIDs for the treatment of various inflammatory conditions such as rheumatoid arthritis, osteoarthritis, low back pain(1). Although it has excellent bioavailability (89\%), its poor aqueous solubility makes absorption and dissolution rate-limited, thus delaying onset of action $(2,3)$. Consequently, an orodispersible formulation of meloxicam was developed that could enhance the bioavailability and extent of bio-absorption of the drug. Meloxicam belongs to the enolic acid group. The antiinflammatory properties of NSAIDs have been explained by their ability to inhibit the enzyme cyclooxygenase $(\mathrm{COX})$, which catalyses the transformation of arachidonic acid to prostaglandin H2 (4). Inhibition of COX-1 is associated with gastrointestinal toxicity while the desired anti-inflammatory activity is mediated by the inhibition of COX-2. Meloxicam proved to have the best COX-2/COX-1 selectivity profile of all compounds tested in a study by Lazer and coworkers, resulting in better gastric tolerability than older drugs that act on both enzymes $(5,6)$. Structurally, meloxicam is closely related to other oxicams such as sudoxicam, piroxicam, isoxicam, and

* Corresponding author: e-mail: muhammadhanif14@yahoo.com 


\section{Tizandine $\mathrm{HCl}$}<smiles>ClC1CCc2nsnc2C1NC1=NCCN1</smiles>

Meloxicam

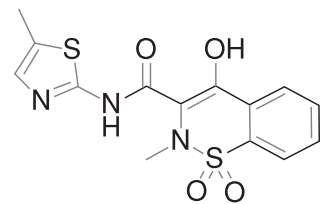

Figure 1. Structural formula of TZN HCl and MLX
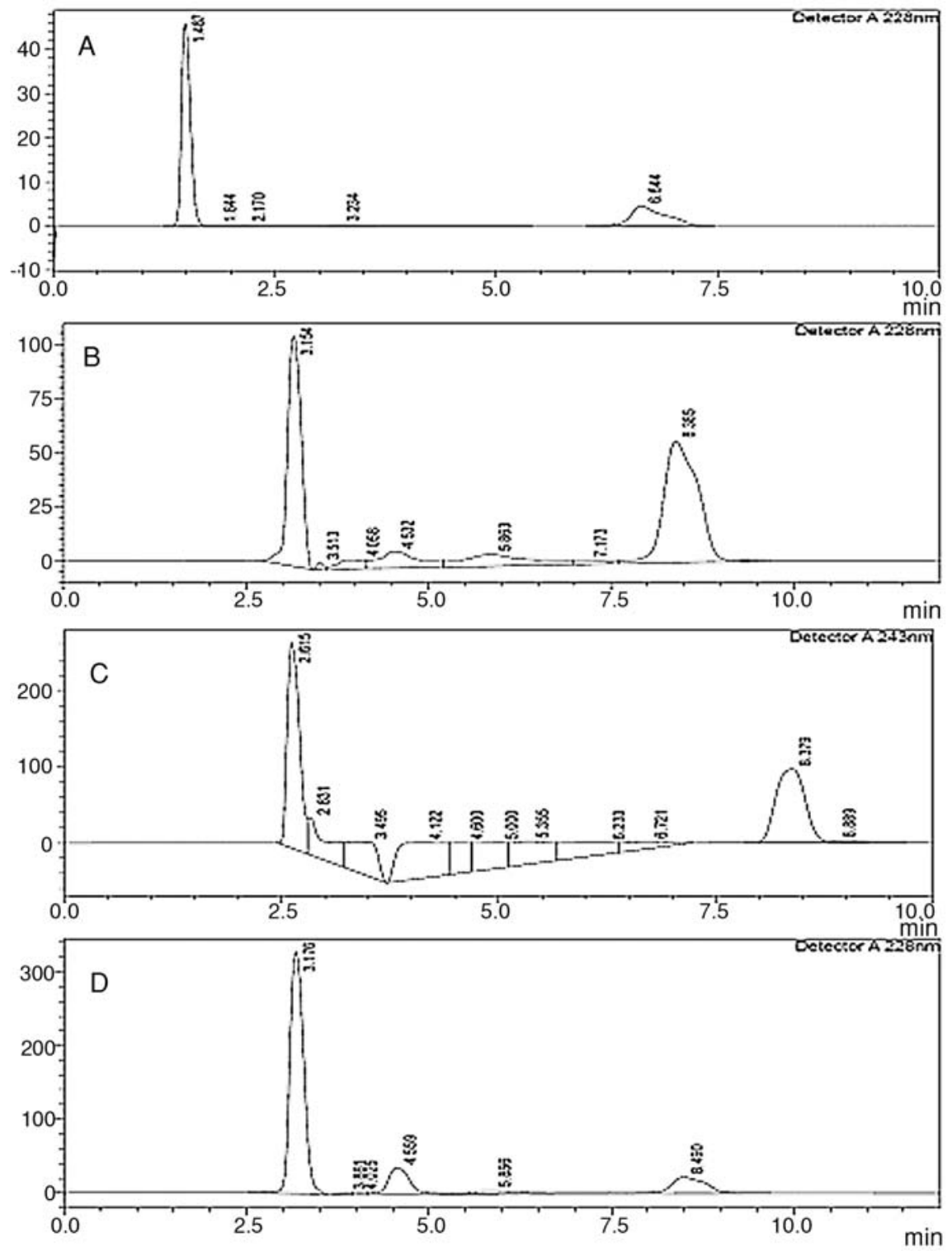

Figure 2. HPLC chromatograms at different chromatographic conditions used for method development. Peaks of TZN HCl and MLX when $\mathrm{pH}$ of the mobile phase was 5.0. (A), Peaks of drugs when $\mathrm{pH}$ of the mobile phase was below 3.0. (B), Eluted peaks of drugs at changed mobile phase composition (C). Peaks when the flow rate was reduced from $0.8 \mathrm{~mL} / \mathrm{min}$ (D) 
tenoxicam but the methyl group on the thiazolyl ring has facilitated its metabolism resulting in a shorter half-life of meloxicam compared to the others (7). Dose of the meloxicam is $7.5 \mathrm{mg}$ to $15 \mathrm{mg}$ daily and its half-life is $20 \mathrm{~h}$. The structural formula of MLX is given in Figure 1.

Different HPLC and RP-HPLC methods have been developed individually or in combination with other drugs for both TZN HCl and MLX. The aim of the current project was to develop a suitable method for the determination of simultaneous determination of $\mathrm{TZN} \mathrm{HCl}$ and MLX.

\section{MATERIALS AND METHODS}

\section{Materials}

TZN HCl and MLX were generously gifted by Pharmedic Laboratories Lahore Pakistan. Orthophosphoric acid, methanol and acetonitrile were purchased from Merck Darmstadt, Germany. Double distilled water was taken from the research laboratories of the department of pharmacy, The University of Lahore, Lahore, Pakistan. All the reagents and chemicals were of HPLC grade.

\section{Instrumentation}

In this project, different instruments were used including HPLC (CTO-20A/20AC SHIMADZU Japan), Column (Kromasil® C18 HPLC Column, $250 \mathrm{~mm} \times 4.6 \mathrm{~mm}, 5 \mu \mathrm{m}$ particle size $), \mathrm{pH}$ meter (25CW microprocessor benchtop $\mathrm{pH} / \mathrm{mV}$ meter (BANTE Instruments, China), Hot plate magnetic stirrer (JISICO J-HSD180 Korea), Weighing balance (JISICO J-HSD180 Korea) and Sonicator (Digital ultrasonic cleaner DSA $100-\mathrm{SK}_{1}$ ).

\section{Method development and validation}

Preparation of mobile phase and standard solutions

A modification of the methods reported by Nalluri in 2012 (8) for the determination of TZN
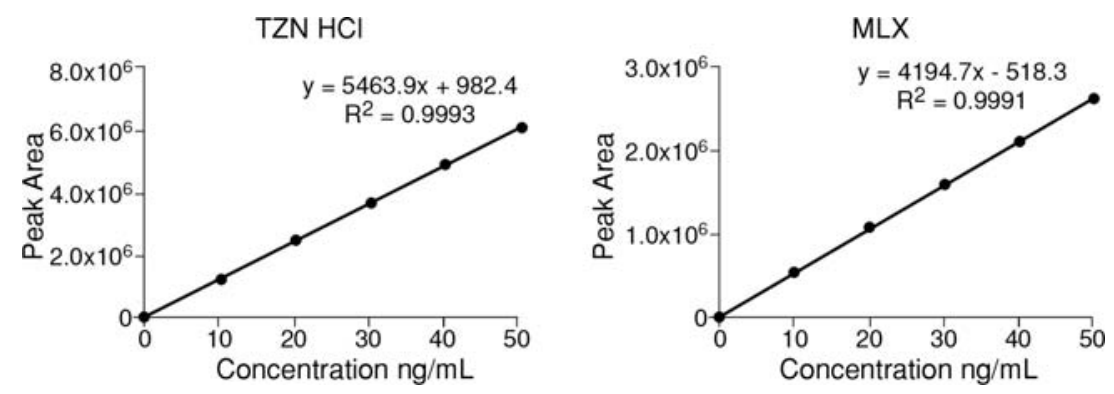

Figure 3. Linearity curves of TZN HCl and MLX in the concentration range of $10 \mathrm{ng} / \mathrm{mL}$ to $50 \mathrm{ng} / \mathrm{mL}$

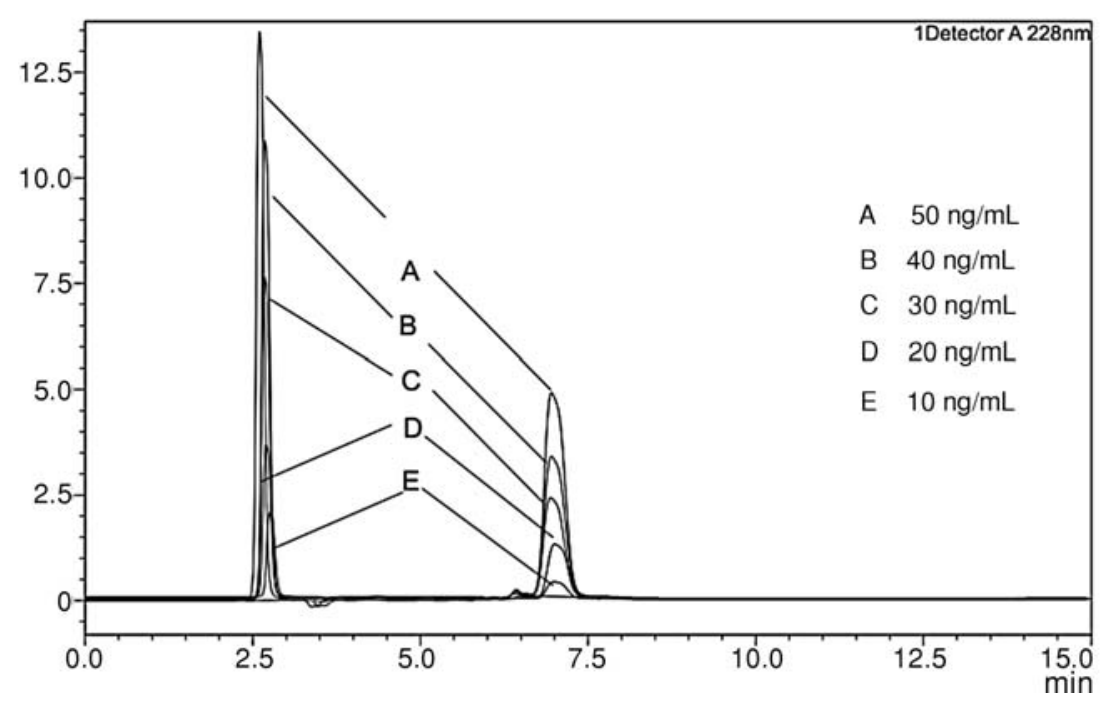

Figure 4. Overlay chromatograms showing linearity of TZN HCl and MLX at different concentrations in mobile phase $(\mathrm{A}=10 \mathrm{ng} / \mathrm{mL}, \mathrm{B}$ $=20 \mathrm{ng} / \mathrm{mL}, \mathrm{C}=30 \mathrm{ng} / \mathrm{mL}, \mathrm{D}=40 \mathrm{ng} / \mathrm{mL}$ and $\mathrm{E}=50 \mathrm{ng} / \mathrm{mL}$ ) 
$\mathrm{HCl}$ while Patel and Amin in 2011 (9) for MLX respectively was used. The mobile phase containing a mixture of methanol and water in the ratio of $8: 2$ and its acidic pH 3.0 was adjusted by orthophosphoric acid in a volumetric flask.

\section{Injection volume and sample run time}

$20 \mu \mathrm{L}$ sample was injected and run for $15 \mathrm{~min}$.

\section{Wavelength of a detection}

$228 \mathrm{~nm}$ for both drugs.

\section{Flow rate}

Variable flow rates of the mobile phase ranging from $0.5 \mathrm{~mL} / \mathrm{min}$ to $1.5 \mathrm{~mL} / \mathrm{min}$ were tried to find out the elution of drugs with reasonable retention time and better resolutions. Finally, the flow rate of the sample was adjusted to $0.8 \mathrm{~mL} / \mathrm{min}$ at ambient temperature and 1400 psig column pressure.

\section{Stock solution}

Both drugs TZN $\mathrm{HCl}$ and MLX were equally weighed and dissolved in $50 \mathrm{~mL}$ methanol. 1.0 $\mu \mathrm{g} / \mathrm{mL}$ solution of drugs was taken as standard and serial dilutions were prepared from 10 to $50 \mathrm{ng} / \mathrm{mL}$ in a mobile phase. The prepared solutions were preserved under controlled conditions of $2-8^{\circ} \mathrm{C}$.

\section{Validation of the developed method}

The developed method was validated for linearity, system suitability, precision, accuracy, robustness, specificity, LOD and LOQ according to ICH guide line.

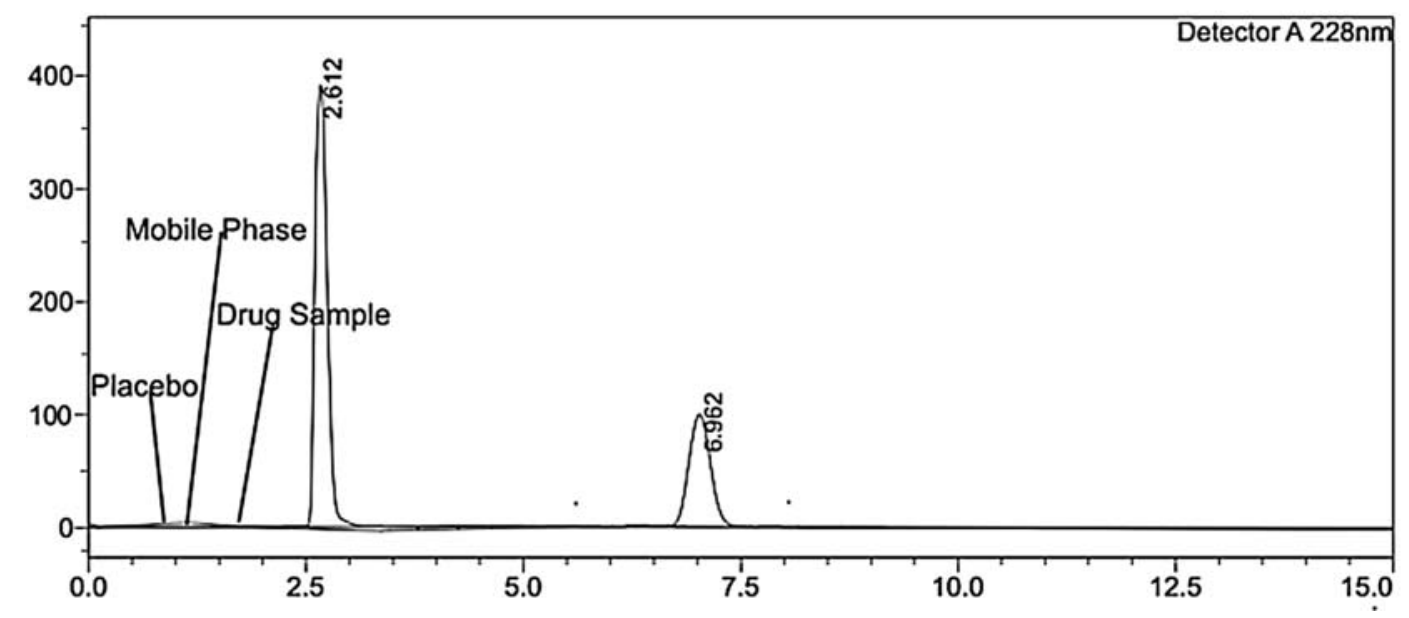

Figure 5. Chromatogram showing specificity of the method after injecting placebo, mobile phase and a sample solution containing TZN HCL and MLX

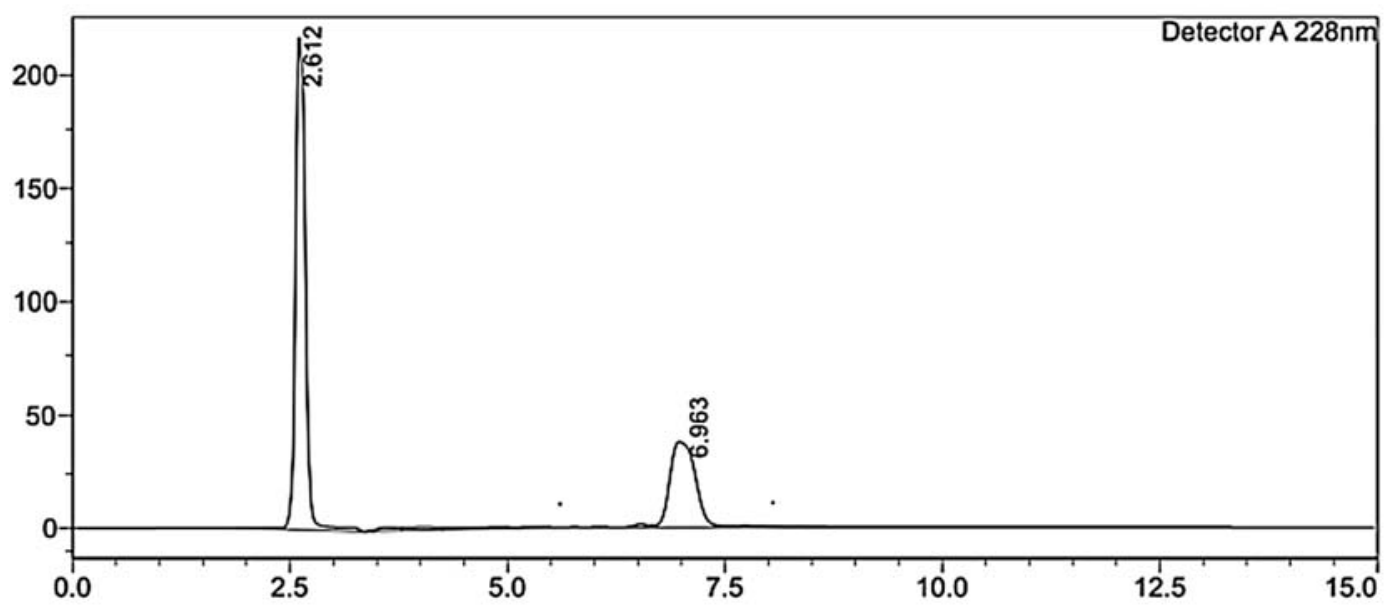

Figure 6. Chromatograms of prepared standard solution of the drugs containing TZN HCl and MLX 


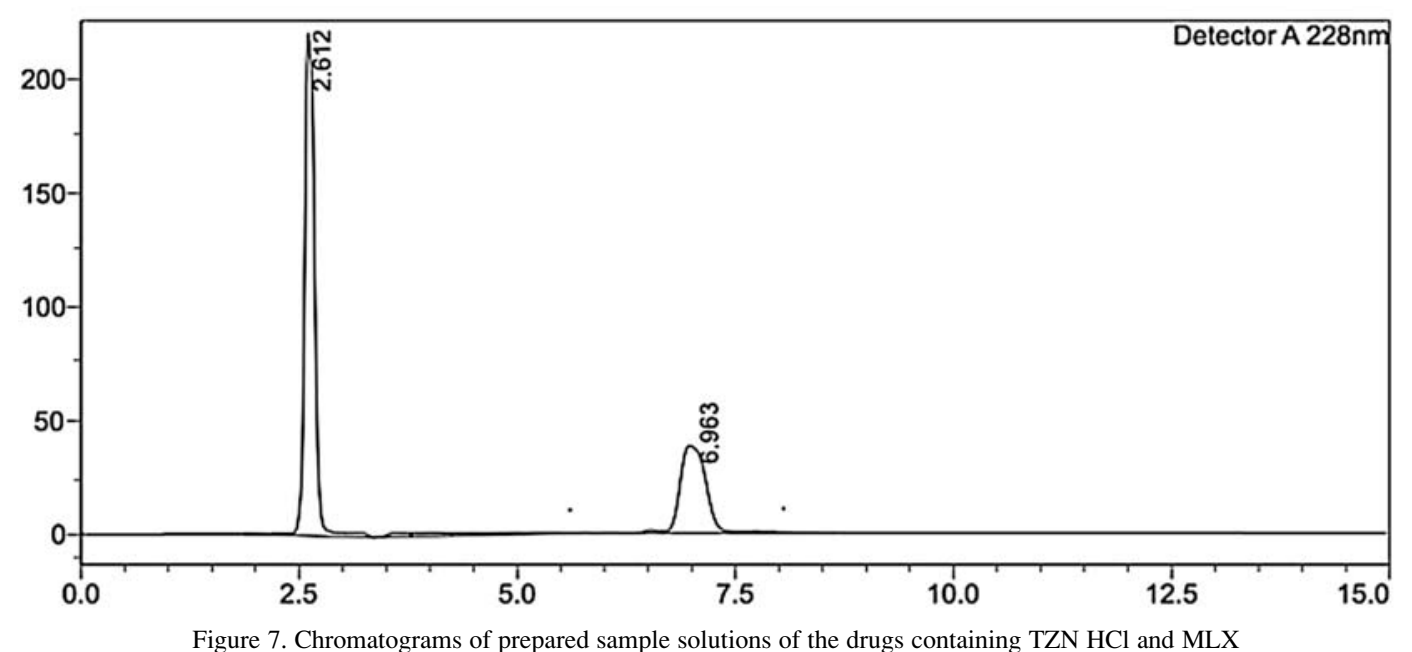

\section{Linearity (Calibration curve)}

The linearity of both drugs was determined by preparing different dilutions of both drugs in the concentration range of 10 to $50 \mathrm{ng} / \mathrm{mL}(10,11)$. A calibration curve was constructed by taking concentrations at $\mathrm{x}$-axis and peaks areas on the $\mathrm{y}$-axis and coefficient of correlation $\left(\mathrm{R}^{2}\right)$ was determined (1214). Samples analysis was performed in triplicate.

\section{System suitability test}

System suitability test was carried out initially with mobile phase followed by injecting 6 injections of the same concentration. Continual injections were injected to assess the suitability of system for developed method on each day of method validation. Features including \% RSD, tailing factor, and theoretical plate were calculated (14).

\section{Intra-day and inter-day precision}

Precision was measured in terms of repeatability of application and measurement. Six replicates of the standard having the a concentration of $30 \mu \mathrm{g} / \mathrm{mL}$ of both TZN HCl and MLX were injected to measure the precision of the method. Inter-day precision was calculated by selecting three different concentrations at three different days while intra-day precision was assessed by analyzing standard solution in triplicate within the linearity range starting from the beginning, middle and at the end of the day (15-17).

\section{Accuracy}

It was determined by performing recovery studies which have been conducted by addition of standard drug solution to pre-analyzed sample solutions of buccal films containing TZN HCl and MLX at three different concentrations levels $(80 \%, 100 \%$ and $120 \%$ ) within the range of linearity (8).

\section{Robustness}

Instrumental conditions including flow rate and organic content in the mobile phase were varied to evaluate the robustness of the developed method (18). Samples were injected under each condition, assay of TZN $\mathrm{HCl}$ and MLX were performed and mean, standard deviation and \% RSD were calculated (19).

\section{Specificity}

It was assessed to find out any intervention by solvents and formulation excipients in the efficacy of the developed method. Six replicate injections of each placebo and the standard drug have been performed and resulted chromatograms were compared for a specificity of the method (14).

\section{Limit of detection (LOD) and limit of quantifica- tion (LOQ)}

LOD was done to find out the minimum detectable amount and LOQ for the measurement of a minimum quantifiable amount of the drugs. They were determined by using equations 1 and 2 respectively (20).

$$
\begin{aligned}
& \mathrm{LOD}=3 \mathrm{O} / \mathrm{S} \\
& \mathrm{LOQ}=10 \mathrm{O} / \mathrm{S}
\end{aligned}
$$

\section{Assay of the prepared formulations}

Four (4) strips of films containing TZN HCl and MLX were taken and dissolve in $100 \mathrm{ml}$ of mobile phase separately. Suitable volumes of both solutions were adjusted to obtain the concentrations 
of TZN HCl $10 \mu \mathrm{g} / \mathrm{mL}$ and MLX $20 \mu \mathrm{g} / \mathrm{mL}$. Filtered samples $(0.22 \mu \mathrm{m})$ were injected for the determination of both drugs.

\section{Solution and mobile phase stability}

Drugs solutions and mobile phase were evaluated for their stability under variable conditions of temperature. They were kept in well-closed measuring flask at ambient temperature for $12 \mathrm{~h}$ followed by $-15^{\circ} \mathrm{C}$ to $-20^{\circ} \mathrm{C}$ for 7 days. $\%$ RSD of the assay of TZN HCl and MLX were calculated during stability studies (21).

\section{Preparation of films}

Solvent casting technique was used for the fabrication of the films. Two layers of films, immediate release layer containing MLX and sustained release layer containing $\mathrm{TZN} \mathrm{HCl}$ were prepared.

\section{Preparation of samples}

4 strips of oral films containing TZN $\mathrm{HCl}$ and MLX were taken and dissolved separately in 100 $\mathrm{mL}$ volumetric flask containing methanol. Suitable aliquots of both solutions were taken, added to another volumetric flask and volume of the solution was adjusted in such a way that the final concentration of both drugs in the solution was $100 \mu \mathrm{g} / \mathrm{mL}$ each. This solution was further diluted to obtain the concentration of both drugs about $20 \mu \mathrm{g} / \mathrm{mL}$. Samples were also filtered through $0.45 \mu \mathrm{m}$ syringe filter.

\section{RESULTS AND DISCUSSION}

RP-HPLC was used for the development of such a method which would be able to determine the TZN $\mathrm{HCl}$ and MLX simultaneously in the buccal films. The retention time of TZN HCl was 2.612 min and of MLX was 6.962 min with a resolution of 2.08 and 3.23 for TZN $\mathrm{HCl}$ and MLX respectively (Table 1).

Feasibility of various solvent systems such as methanol-water, acetonitrile-water and acetonitrile-phosphate buffer etc., in different compositions, injected at different flow rates $(0.5-1.5$ $\mathrm{mL} / \mathrm{min})$, variable $\mathrm{pH}(2.0-7.0)$ and at different detection wavelengths was assessed. In results, different retention times and peaks behaviors were recorded (Fig. 2) (22, 23). Attempts were made for the optimization of experimental conditions in such a way that, to adjust the composition of mobile phase, $\mathrm{pH}$ was fixed to 3.0 and to evaluating the effect of mobile phase $\mathrm{pH}$, the mobile phase composition was fixed as methanol-water $(8: 2, \mathrm{v} / \mathrm{v})$. Substantially variations were recorded in the retention time of all analytes upon a change in the $\mathrm{pH}$,

Table 1. System suitability studies of developed method for MLX and TZN HCl.

\begin{tabular}{|c|c|c|c|c|c|c|}
\hline Drugs & Peak area & \%RSD & Theoretical plates & Tailing factor & Resolution & Retention time \\
\hline TZN HCl & 3772247 & 0.09885 & 2398 & 1.08 & 2.08 & 2.612 \\
\hline MLX & 1629648 & 0.15504 & 3812 & 0.93 & 3.23 & 6.962 \\
\hline \multicolumn{2}{|l}{ USP recommendation } & $<2$ & $>2000$ & 0.8 to 1.5 & $>2$ & \\
\hline
\end{tabular}

Values are presented as mean $(n=6)$

Table 2. Data of precision studies for the developed method for TZN HCl and MLX $(n=6)$.

\begin{tabular}{|c|c|c|}
\hline Injections & $\begin{array}{c}\text { TZN HCl } \\
\text { Average AUC }\end{array}$ & $\begin{array}{c}\text { MLX } \\
\text { Average AUC }\end{array}$ \\
\hline 1 & 3780006 & 1630987 \\
\hline 2 & 3772112 & 1625981 \\
\hline 3 & 3771699 & 1627967 \\
\hline 4 & 3769987 & 1634081 \\
\hline 5 & 3771599 & 1629931 \\
\hline 6 & 3768079 & 1628939 \\
\hline Mean & 3772247 & 1629648 \\
\hline \%SD & 0.098846 & 0.155035 \\
\hline
\end{tabular}


Table 3. Inter-day and intra-day precision data of TZN HCl and MLX $(n=6)$.

\begin{tabular}{|c|c|c|c|c|c|}
\hline \multirow{2}{*}{ Drugs } & \multirow{2}{*}{$\begin{array}{c}\text { Actual } \\
\text { Amount }\end{array}$} & \multicolumn{4}{|c|}{ Concentration found } \\
\cline { 2 - 6 } & & Intra-day (Mean \pm SD) & \%RSD & Inter-day (Mean \pm SD) & $\%$ RSD \\
\hline \multirow{3}{*}{ TZN } & 3.2 & $3.19 \pm 1.20$ & 0.55 & $3.18 \pm 0.92$ & 0.86 \\
\cline { 2 - 6 } HCl & 4 & $3.97 \pm 0.60$ & 0.23 & $3.91 \pm 1.01$ & 1.10 \\
\cline { 2 - 6 } & 4.8 & $4.96 \pm 1.00$ & 0.57 & $4.93 \pm 1.21$ & 0.84 \\
\hline \multirow{3}{*}{ MLX } & 6 & $5.91 \pm 0.50$ & 0.33 & $5.88 \pm 0.97$ & 0.54 \\
\cline { 2 - 6 } & 7.5 & $7.48 \pm 0.50$ & 0.98 & $7.39 \pm 0.37$ & 0.71 \\
\cline { 2 - 6 } & 9 & $8.98 \pm 0.50$ & 0.42 & $8.87 \pm 0.63$ & 0.41 \\
\hline
\end{tabular}

Table 4. Recovery studies of TZN HCl and MLX after injecting specific concentrations of TZN HCl and MLX.

\begin{tabular}{|c|c|c|c|c|c|c|}
\hline \multirow{2}{*}{ Drugs } & $\begin{array}{c}\text { Concentration } \\
\text { at specific } \\
\text { levels (\%) }\end{array}$ & \%RSD & $\begin{array}{c}\text { Actual } \\
\text { amount } \\
(\mathrm{mg})\end{array}$ & $\begin{array}{c}\text { Amount } \\
\text { recover } \\
(\mathrm{mg})\end{array}$ & \% recovery & Mean recovery \\
\hline \multirow{3}{*}{$\begin{array}{c}\mathrm{TZN} \\
\mathrm{HCl}\end{array}$} & 80 & 0.012641 & 3.2 & 3.18 & 99.43 & 99.63 \\
\cline { 2 - 7 } & 100 & 0.008008 & 4 & 3.96 & 99.01 & 100.47 \\
\hline \multirow{3}{*}{ MLX } & 120 & 0.006259 & 4.8 & 4.82 & 100.71 & 98.18 \\
\cline { 2 - 7 } & 100 & 0.002709 & 6 & 6.04 & 100.88 & 9.92 \\
\hline
\end{tabular}

composition of mobile phase and flow rates. When the $\mathrm{pH}$ decreased from 7.0 to 5.0, the retention times of analytes were found to be very short on the other hand; further decrease in the $\mathrm{pH}$ from 5.0 to 3.0, an increase in the retention times was noticed. However, below $\mathrm{pH} 3.0$, although the retention times were increased, symmetry of the peaks were diminished. At pH 3.0 peaks with good symmetry and suitable retention times were obtained. When the composition of mobile phase was changed from methanol-water, asymmetric peaks with unsuitable retention times and variable peaks area were eluted, may be due to a change in the solubility of analytes in the mobile phase. The other reason was may be the change in affinity of analytes and the stationary phase to each other. By adjusting the flow rate greater than $0.8 \mathrm{~mL} / \mathrm{min}(1.0 \mathrm{~mL} / \mathrm{min}$ to 1.5 $\mathrm{mL} / \mathrm{min}$ ) peaks with short retention times and lesser resolutions appeared, but when flow rate was decreased to less than $0.8 \mathrm{~mL} / \mathrm{min}$ retention times of the peaks were increased but unsymmetrical peaks were appeared. For the better elution of TZN HCl and MLX, detection wavelength was also varied in the range of 220 to $365 \mathrm{~nm}$. Certain wavelengths were failing in simultaneous detection of both drugs. Finally the chromatographic conditions as mobile phase having composition methanol-water in the ratio of $8: 2$, adjusted $\mathrm{pH}$ to 3.0 , flow rate of 0.8 $\mathrm{mL} / \mathrm{min}$, ambient temperature and Column, Kromasil® C18 (250 mm $\times 4.6$ mm, $5 \mu \mathrm{m}$ particle size) was selected for HPLC analysis of TZN HCl and MLX.

\section{Linearity (Calibration curve)}

Calibration curves are considered useful tools for quantification of the drugs from samples. The linearity of working standard solutions of TZN $\mathrm{HCl}$ and MLX was assessed by injecting 6 injections of different concentrations ranging from $10 \mathrm{ng} / \mathrm{mL}$ to $50 \mathrm{ng} / \mathrm{mL}$ and their calibration curves were constructed. Emara LH and her co-researchers have adopted the similar technique to determine the linearity of MLX and Qi ML and his co-workers for TZN HCl by using HPLC method for quantification of drugs $(11,24)$. Results showed that linearity of both drugs in the selected concentration range was satisfactory with correlation coefficients values 0.9993 and 0.9991 for TZN HCl and MLX respectively and were in accordance to the reported results of above mentioned researchers. Figures 3 and 4 was the proves of good linear behaviour of both drugs in selected chromatographic conditions. 


\section{System suitability studies}

The results of the system suitability studies guarantee the appropriateness of the suggested HPLC method for analysis of TZN HCl and MLX. The tailing factor was found to be 1.08 and 0.93 , and the resolution was 2.08 and 3.23, signifying that drugs peaks were symmetric and well resolved. The $\%$ RSD of six sequential injections was found to be 0.098 and $0.155 \%$ for TZN HCl and MLX respectively, therefore exhibited good results of injection repeatability. The number of a theoretical plate for TZN HCl were 2398 and 3812 for MLX, hence proving good column efficiency (Table 1).

\section{Intra-day and inter-day precision}

The developed method was found to be accurate for the estimation of both drugs. After six replicas of the same strength $(30 \mu \mathrm{g} / \mathrm{mL})$, the calculated $\%$ RSD was $0.0988 \%$ for TZN $\mathrm{HCl}$ and $0.155 \%$ for MLX (Table 2), indicating good precision level of the developed method. Results presented in table for inter-day and intra-day precision data of $\mathrm{TZN} \mathrm{HCl}$ and MLX were evidence that the method was precise. \% RSD of intra-day and inter-day data for both drugs was less than 2 (Table 3). No significantly variable outcome was detected on retention time and percentage recoveries when small changes were made to chromatographic conditions.

\section{Accuracy}

The current study was also validated for accuracy of the system for developed method and recovery studies were calculated. Method was found to be quite accurate for both drugs, providing $99.63 \%$ and $99.92 \%$ of TZN HCl and MLX respectively (Table 4 ).

\section{Robustness}

Robustness of the method was confirmed by slight variations in the instrumental conditions such as flow rate, which was slowing down to $0.76 \mathrm{~mL} / \mathrm{min}$ from $0.8 \mathrm{~mL} / \mathrm{min}( \pm 5 \%)$ and methanolic contents at \pm $2 \%$. Variability was found ineffectual on the developed method and calculated \% RSD was $0.099 \%$, and $0.157 \%$ for $\mathrm{TZN} \mathrm{HCl}$ and MLX respectively.

\section{Specificity}

Specificity of the method was analyzed and no interference of active drug materials was observed by performing separate injections of standard, placebo, and mobile phase. No any interfering peaks in the retention time ranges of both drugs appeared and retention time of TZN HCl and MLX were persisted to be constant as 2.612 and 6.962 min respectively (Fig. 5).

\section{LOD and LOQ}

When LOD and LOQ studies were performed, it was observed that LOD values were $0.5 \mathrm{ng}$ and 3.1 $\mathrm{ng} / \mathrm{mL}$ while LOQ values were $1.0 \mathrm{ng}$ and 4.3 $\mathrm{ng} / \mathrm{mL}$ for $\mathrm{TZN} \mathrm{HCl}$ and MLX respectively.

\section{Assay of prepared film formulations containing TZN HCl and MLX}

Assay of the developed films formulations When assay studies of developed films were studied (Fig. 6, 7), films of TZN HCl showed $99.75 \%$ and MLX showed $99.91 \%$ of the drug contents. Comparison of currently developed method indicating comparative sensitivity of developed method for TZN HCl but better for MLX.

\section{Stability of solution and mobile phase}

Drugs solution, as well as mobile phase, showed good stability under provided conditions. The results were compared with freshly prepared mobile phase and drug solution. The accuracy of the method was found between the range of 95 to $98 \%$ for both TZN HCl and MLX respectively.

\section{CONCLUSION}

A lot of attempts were made for the selection of suitable mobile phase, its $\mathrm{pH}$, and flow rate. Various combination of aqueous and organic solvents such as water and acetonitrile, water, acetonitrile and methanol, phosphate buffer and acetonitrile, buffer and methanol etc at different $\mathrm{pH}$ values like, 7.2, $6.8,6.5$, and 3 etc at various flow rates varying 1.0 $\mathrm{mL} / \mathrm{min}$ to $0.5 \mathrm{~mL} / \mathrm{min}$ were tried. However, peaks with good shape and resolution time were obtained in the selected method. Good percentage recovery, precision, accuracy, and linearity over the selected concentration ranges proved that the selected method is suitable and valid for the simultaneous determination of TZN HCl and MLX in pure as well as in dosage form.

\section{Declarations}

The work done in the current project is original work. All authors unanimously agree to submit the article to the journal.

\section{Ethics approval and consent to participate Not applicable}

\section{Consent for publication}

Not applicable 


\section{Availability of data and material}

All data generated or analyzed during this study are included in this published article (and its supplementary information files).

\section{Funding}

There is no any internal or external source of funding for this project or publication.

\section{Authors contribution}

$\mathrm{MH}$ has designed the project and reviewed the final manuscript, $\mathrm{MZ}$ has done the experiments, wrote the initial document and HM has contributed in performing HPLC analysis and calculation of the results.

\section{Competing interests}

The authors declare that they have no competing interests

\section{Acknowledgment}

Authors are thankful for the kind support of Dr. Kishwar Sultana, Associate Professor Faculty of Pharmacy and other lab staff of central research lab Faculty of Pharmacy, The University of Lahore for the completion of the current project.

\section{REFERENCES}

1. Akhlaq M., Khan G.M., Wahab A., Khan A., Hussain A. et al.: J. Adv. Pharm. Technol. Res. 2, 151 (2011).

2. Battu P.R.: Indian J. Pharm. Sci. 69, 281 (2007).

3. Emara L.H., Emam M.F., Taha N.F., Raslan H.M., El-Ashmawy A.A.: J. Appl. Pharm. Sci. 6, 13 (2016).

4. Fuster J., Negro S., Salama A., FernándezCarballido A., Marcianes P. et al.: Int. J. Pharm. 491, 310 (2015).

5. Ganorkar S.B., Dhumal D.M., Shirkhedkar A.A.: Arab. J. Chem. 10, 273 (2017).

6. Hanif M., Nazir N., Zia M.U., Chudhary B.A., Abbas G. et al.: Lat. Am. J. Pharm. 34, 1737 (2015).
7. Iancu V., Roncea F., Cazacincu R.G., Lupu C.E., Miresan H. et al.: Farmacia 64, 210 (2016).

8. Kass M.A. Becker B.: Am. J. Ophthalmol. 81, 368 (1976).

9. Lazer E.S., Miao C.K., Cywin C.L., Sorcek R., Wong H.C. et al.: J. Med. Chem. 40, 980 (1997).

10. Lu C., Jia Y., Yang J., Jin X., Song Y. et al.: Acta Pharm. Sin. B 2, 205 (2012).

11. Malamatari M., Somavarapu S., Taylor K.M. Buckton G.: Expert Opin. Drug Deliv. 13, 435 (2016).

12. Mohammadi A., Rezanour N., Dogaheh M.A., Bidkorbeh F.G., Hashem M. et al.: J. Chromatogr. B 846, 215 (2007).

13. Nalluri B.N., Sushmitha K., Sunandana B., Babu D.P.: J. Appl. Pharm. Sci. 2, 111 (2012).

14. Ochi M., Kimura K., Kanda A., Kawachi T., Matsuda A. et al.: AAPS Pharm. Sci. Tech. 17, 932 (2016).

15. Patel M.M., Amin A.F.: Drug Deliv. 18, 281 (2011).

16. Pethkar S.: World J. Pharm. Pharm. Sci. 5, 1452 (2016).

17. Qi M.L., Wang P., Wang L.: Anal. Chim. Acta 478, 171 (2003).

18. Segundo M.A., Abreu V.L., Osório M.V., Nogueira S., Lin P.K.T. et al.: J. Pharm. Biomed. Anal. 120, 290 (2016).

19. Şenkardeş S., Özaydın T., Uğurlu T., Küçükgüzel Ş.G.: Marmara Pharm. J. 21 (2017).

20. Shah Y., Iqbal Z., Ahmad L., Khan A., Khan M.I., Nazir S., Nasir F.: J. Chromatogr. B 879, 557 (2011).

21. Shaji J., Varkey D.: Int. J. Pharm. Sci. Rev. Res. 12, 152 (2012).

22. Shao Y., Alluri R., Mummert M., Koetter U., Lech S.: J. Pharm. Biomed. Anal. 35, 625 (2004).

23. Shrivastava A., Gupta V.: Chron. Young Sci. 2, 21 (2011).

24. Woolf T.F., Radulovic L.L.: Drug Metab. Rev. 21, 255 (1989).

Received: 03.11.2017 